\title{
Analisis Kebutuhan Energi Pabrik Kelapa Sawit Sungai Rungau Mill
}

\author{
Lia Laila ${ }^{1}$, M. Yusuf Qoderi ${ }^{2}$ \\ Teknologi Pengolahan Sawit, Fakultas Vokasi, Institut Teknologi Sains Bandung, Bekasi, Indonesia \\ Teknologi Pengolahan Sawit, Fakultas Vokasi, Institut Teknologi Sains Bandung, Bekasi, Indonesia
}

\begin{abstract}
Abstrak
Pabrik Kelapa Sawit Sungai Rungau Mill mempunyai bahan bakar biomassa yang sangat melimpah. Akan tetapi penggunaan sumber bahan bakar ini harus dioptimalkan agar performa pabrik dapat berjalan dengan baik dengan cara mengkaji kebutuhan energi secara aktual. Jumlah dan komposisi bahan bakar yang digunakan harus diperhatikan sesuai dengan kebutuhan. Kelebihan atau kekurangan bahan bakar dapat menyebabkan terjadinya penurunan tekanan dan komposisi yang tidak tepat yang akan menyebabkan perambatan panas yang kurang baik. Tujuan dari penelitian ini adalah mengkaji kebutuhan dan komposisi bahan bakar yang sesuai dengan energi yang dibutuhkan untuk proses produksi kelapa sawit. Pabrik Kelapa Sawit Sungai Rungau Mill mempunyai sistem pembangkit uap yang mengubah air menjadi steam untuk menggerakan turbin uap dengan bahan bakar serabut dan cangkang hasil dari proses produksi tandan buah segar. Metode yang digunakan dalam penelitian ini adalah pengukuran langsung di Pabrik Kelapa Sawit Sungai Rungau Mill dengan berbagai instrumen dan peralatan yang ada. Dari proses produksi tandan buah segar dengan kapasitas 82,3 ton/jam diperoleh serabut dan cangkang masing-masing sebanyak 11,36 ton/jam dan 4,73 ton/jam. Kemudian bahan bakar tersebut dipakai untuk boiler dengan jumlah serabut 10,60 ton sedangkan cangkang 2,73 ton dengan persentase $79,49 \%$ serabut dan $20,51 \%$ cangkang. Selanjutnya pembakaran dalam boiler menghasilkan steam dengan jumlah 43,2 ton/jam yang digunakan untuk menggerakan turbin sehingga menghasilkan daya listrik sebesar $1475 \mathrm{kWh}$.
\end{abstract}

Kata-kunci: bahan bakar, boiler, energi, steam

\section{PENDAHULUAN}

Pabrik Kelapa Sawit Sungai Rungau Mill mempunyai bahan bakar biomassa yang sangat melimpah. Akan tetapi penggunaan sumber bahan bakar ini harus dioptimalkan agar performa pabrik dapat berjalan dengan baik dengan cara mengkaji kebutuhan energi secara aktual. Jumlah dan komposisi bahan bakar yang digunakan harus diperhatikan sesuai dengan kebutuhan. Kelebihan atau kekurangan bahan bakar dapat menyebabkan terjadinya penurunan tekanan dan komposisi yang tidak tepat yang akan menyebabkan perambatan panas yang kurang baik ${ }^{3)}$. 


\subsection{Tujuan Penelitian}

Tujuan dari penelitian ini antara lain adalah:

1. Menghitung ketersediaan dan kebutuhan energi di Pabrik Kelapa Sawit Sungai Rungau Mill secara aktual,

2. Menghitung persentase bahan bakar yaitu serabut dan cangkang,

3. Menghitung bahan bakar cangkang yang dapat dihemat karena mempunyai nilai ekonomis yang tinggi.

\subsection{Kajian Pustaka}

\section{Siklus rankine:}

Siklus rankine adalah siklus teoritis yang mendasari siklus kerja dari suatu pembangkit daya uap. Siklus rankine sederhana dapat dilihat pada Gambar 1. ${ }^{1)}$

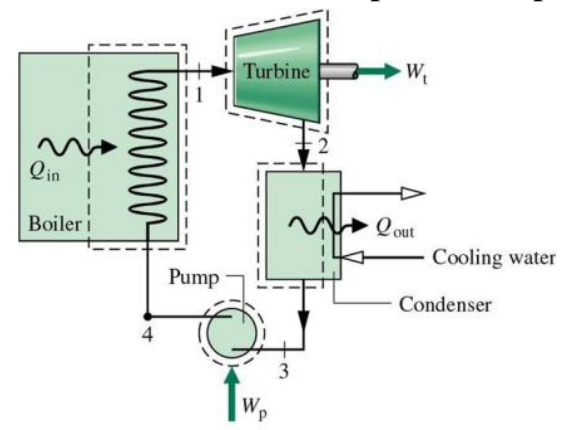

(a)

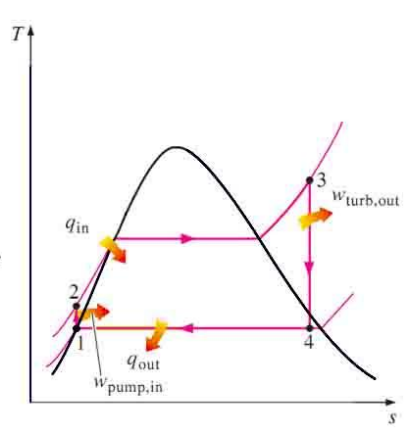

(b)

Gambar 1. (a). Komponen-komponen siklus rankine, (b). Siklus rankine sederhana ${ }^{1)}$

Siklus rankine ideal memiliki tahapan proses sebagai berikut :

- 1-2 isentropic compression in pump

- 2-3 constant pressure heat addition in boiler

- 3-4 isentropic expansion in turbine

- 4-1 constant pressure heat rejection in condenser

\section{Boiler:}

Boiler, kondensor dan evaporator mempunyai tujuan utama memindahkan masa dari atau ke medium yang mengalir secara tunak. Untuk mengubah fluida dari fase cair jenuh menjadi uap jenuh diperlukan kalor. Pembakaran akan melepas sejumlah besar kalor dan diserap oleh zat kerja sehingga suhu dan entalpi zat kerja akan meningkat. Diandaikan bahwa perbedaan energi kinetik air masuk dan uap yang keluar dapat diabaikan. Proses terjadi pada tekanan konstan karena pada boiler tidak ada bagian yang berpindah, maka tidak ada usaha yang dilakukan ${ }^{2}$.

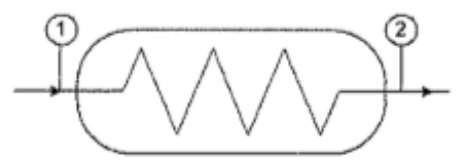

Gambar 2. Skematik boiler ${ }^{2)}$. 
Karena $\mathrm{h}_{2}>\mathrm{h}_{1}$ maka energi akan berharga positif yang menunjukan bahwa energi masuk ke sistem dari bahan bakar dan diserap oleh zat kerja.

$$
\mathrm{Q}=\dot{\mathrm{m}}\left(\mathrm{h}_{2}-\mathrm{h}_{1}\right)
$$

Untuk aliran tunak,

$$
\dot{\mathrm{m}}_{1}=\dot{\mathrm{m}}_{2}=\dot{\mathrm{m}}
$$

\section{Bahan Bakar:}

Pabrik Kelapa Sawit mempunyai sumber bahan bakar serabut dan cangkang yang berasal dari proses produksi kelapa sawit itu sendiri. Gambar 3 menunjukan bentuk serabut dan cangkang yang ada di pabrik kelapa sawit.
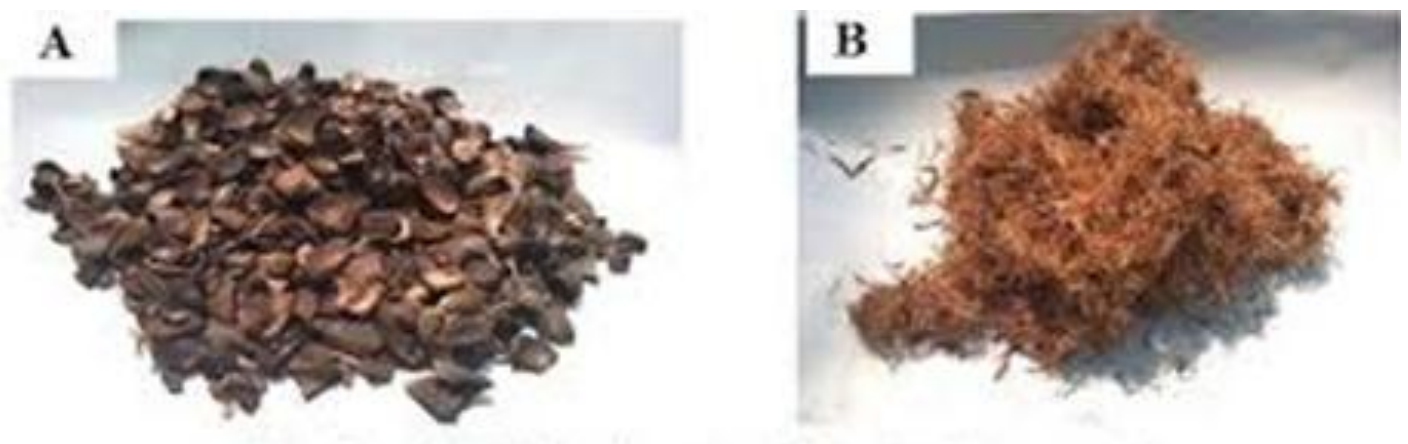

Gambar 3. A (cangkang), B (serabut) ${ }^{3)}$.

Apabila pemakaian cangkang terlalu banyak daripada serabut akan menghambat proses pembakaran akibat penumpukan arang dan nyala api kurang sempurna, dan jika cangkang digunakan sedikit, panas yang dihasilkan akan rendah, karena cangkang apabila dibakar akan mengeluarkan panas yang besar.

Panas yang dihasilkan serabut jumlahnya lebih kecil dari yang dihasilkan oleh cangkang, oleh karena itu perbandingan lebih besar serabut daripada cangkang. Disamping serabut lebih cepat habis menjadi abu apabila dibakar, pemakaian serabut yang berlebihan akan berdampak buruk pada proses pembakaran karena dapat menghambat proses perambatan panas pada pipa water wall, akibat abu hasil pembakaran berterbangan dalam ruang dapur dan menutupi pipa water wall, di samping mempersulit pembuangan dari pintu ekspansion door (pintu keluar untuk abu dan arang) akibat terjadinya penumpukan yang berlebihan. Nilai kalor serabut dan cangkang dapat dilihat pada Tabel 1.

Tabel 1. Bahan bakar dan energi ${ }^{4)}$.

\begin{tabular}{ccccc}
\hline Bahan Bakar & Jumlah $(\mathrm{kg})$ & \% to TBS & Kalor Jenis $(\mathrm{kJ} / \mathrm{kg})$ & Jumlah Energi (GJ/hr) \\
\hline Serabut & 10000 & 12,5 & 2637 & 26,37 \\
Cangkang & 4600 & 5,75 & 4105 & 18,83 \\
\hline
\end{tabular}

Sedangkan jumlah serabut dan cangkang dari proses produksi PKS dengan TPH 80 ton/jam dapat dilihat pada Tabel 2. 
Tabel 2. Bahan bakar dan energi ${ }^{4}$.

\begin{tabular}{ccc}
\hline No & Stasiun & kg uap/ton TBS \\
\hline 1 & Sterilizer & 260 \\
2 & Digester & 60 \\
3 & Nut \& Kernel & 130 \\
4 & Klarifikasi & 100 \\
\hline & Total & 550 \\
\hline
\end{tabular}

\section{METODE}

Tujuan dari pengujian ini adalah untuk menghitung jumlah dan persentase bahan bakar aktual Pabrik Kelapa Sawit Sungai Rungau Mill. Tempat pengujiannya adalah fuel distributing conveyor \& retrival conveyor. Alat dan bahan yang harus dipersiapkan adalah timbangan, karung plastik, sekop, stopwacth, dan timbangan analitik. Gambar 4 adalah metode untuk menghitung jumlah bahan bakar yang masuk ke boiler.

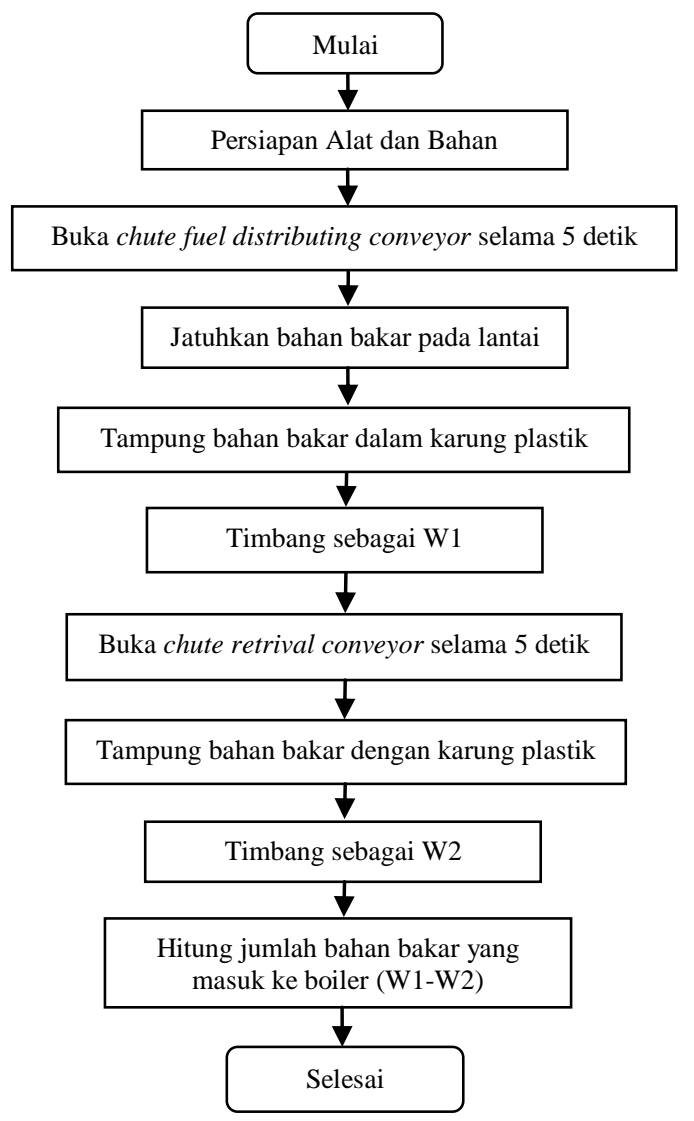

(a)

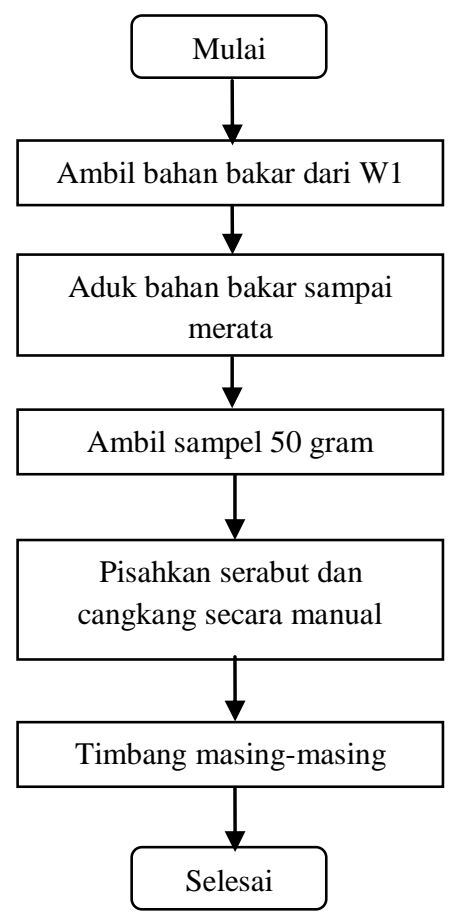

Gambar 4. (a) Flowchart pengujian jumlah bahan bakar, (b) Flowchart pengujian komposisi bahan bakar 


\section{PEMBAHASAN DAN DISKUSI}

\subsection{Hasil Pengujian Bahan Bakar}

Dari hasil pengujian jumlah bahan bakar serabut dan cangkang yang tersedia adalah 14,3 ton dan yang terpakai adalah 13,3 ton (seperti ditunjukkan pada Tabel 3), sedangkan nilai kalor dari serabut dan cangkang dan persentase bahan bakar berturut-turut disajikan pada Tabel 4 dan Tabel 5.

Tabel 3. Hasil pengujian jumlah bahan bakar

\begin{tabular}{|c|c|c|c|c|c|c|c|c|}
\hline \multirow[b]{2}{*}{ No } & \multicolumn{2}{|c|}{ Boiler 1} & \multicolumn{2}{|c|}{ Boiler 2} & \multirow[b]{2}{*}{$\mathrm{t}(\mathrm{s})$} & \multirow[b]{2}{*}{$\mathrm{W}_{1}$ (ton) } & \multirow[b]{2}{*}{$\mathrm{W}_{2}$ (ton) } & \multirow[b]{2}{*}{$\mathrm{W}_{1}-\mathrm{W}_{2}$ (ton) } \\
\hline & P (barg) & $\begin{array}{l}\text { S.flow } \\
\text { (ton/h) }\end{array}$ & P (barg) & $\begin{array}{l}\text { S.flow } \\
\text { (ton/h) }\end{array}$ & & & & \\
\hline 1 & 19,6 & 24 & 19,8 & 20 & 5 & 0,0220 & 0,0025 & 0,0195 \\
\hline 2 & 19,4 & 23 & 19,6 & 19 & 5 & 0,0199 & 0,0015 & 0,0184 \\
\hline 3 & 19,7 & 23 & 19,8 & 19 & 5 & 0,0215 & 0,0025 & 0,019 \\
\hline 4 & 19,3 & 23 & 19,5 & 21 & 5 & 0,0185 & 0 & 0,0185 \\
\hline 5 & 19,4 & 23 & 19,7 & 21 & 5 & 0,0192 & 0 & 0,0192 \\
\hline 6 & 19,5 & 23 & 18,3 & 20 & 5 & 0,0200 & 0 & 0,02 \\
\hline 7 & 19,3 & 22 & 19,4 & 23 & 5 & 0,0185 & 0,0012 & 0,0173 \\
\hline 8 & 19,6 & 22 & 19,8 & 20 & 5 & 0,0196 & 0,0016 & 0,018 \\
\hline 9 & 19,5 & 23 & 19,8 & 20 & 5 & 0,0199 & 0,0024 & 0,0175 \\
\hline 10 & 19,3 & 22 & 19,6 & 21 & 5 & 0,0194 & 0,0016 & 0,0178 \\
\hline \multirow{2}{*}{$\bar{x}$} & \multirow{2}{*}{19,46} & \multirow{2}{*}{22,8} & \multirow{2}{*}{19,53} & \multirow{2}{*}{20,4} & 5 & 0,0199 & 0,0013 & 0,0185 \\
\hline & & & & & 3600 & 14,2927 & 0,9576 & 13,335 \\
\hline
\end{tabular}

Keterangan $\quad: \quad \mathrm{W}_{1}$ : Berat bahan bakar sebelum masuk boiler

$\mathrm{W}_{2}$ : Sisa bahan bakar

$\mathrm{W}_{1}-\mathrm{W}_{2}$ : Bahan bakar yang masuk ke boiler

Tabel 4. Nilai Kalor Serabut dan Cangkang

\begin{tabular}{cccc}
\hline Bahan Bakar & Persentase & Tersedia (ton) & Terpakai (ton) \\
\hline Serabut & $79,49 \%$ & 11,36 & 10,6 \\
Cangkang & $20,51 \%$ & 2,93 & 2,73 \\
\hline
\end{tabular}

Tabel 5. Komposisi Bahan Bakar Serabut dan Cangkang

\begin{tabular}{cccccc}
\hline No & Massa Sampel $(\mathrm{g})$ & Cangkang $(\mathrm{g})$ & Serabut $(\mathrm{g})$ & \% Serabut & \%Cangkang \\
\hline 1 & 50,02 & 9,89 & 40,13 & $80,20 \%$ & $19,80 \%$ \\
2 & 50,06 & 9,97 & 40,09 & $80,10 \%$ & $19,90 \%$ \\
3 & 50,94 & 9,06 & 41,88 & $82,10 \%$ & $17,90 \%$ \\
4 & 50,45 & 10,32 & 40,13 & $79,54 \%$ & $20,46 \%$ \\
5 & 50 & 10,25 & 39,75 & $79,50 \%$ & $20,50 \%$ \\
6 & 50,76 & 10,51 & 40,25 & $79,30 \%$ & $20,70 \%$ \\
7 & 50,18 & 11,14 & 39,04 & $77,80 \%$ & $22,20 \%$ \\
8 & 50,24 & 11,08 & 39,16 & $77,95 \%$ & $22,05 \%$ \\
9 & 50,18 & 10,28 & 39,9 & $79,50 \%$ & $20,50 \%$ \\
10 & 50,12 & 10,64 & 39,48 & $78,80 \%$ & $21,20 \%$ \\
\hline $\bar{x}$ & 50,295 & 10,314 & 39,981 & $79,49 \%$ & $20,51 \%$ \\
\hline
\end{tabular}




\subsection{Kebutuhan Energi}

Energi yang dibutuhakan untuk membangkitkan uap di boiler PKS Sungai Rungau Mill dapat dihitung dengan diagram T-S pada Gambar 5.

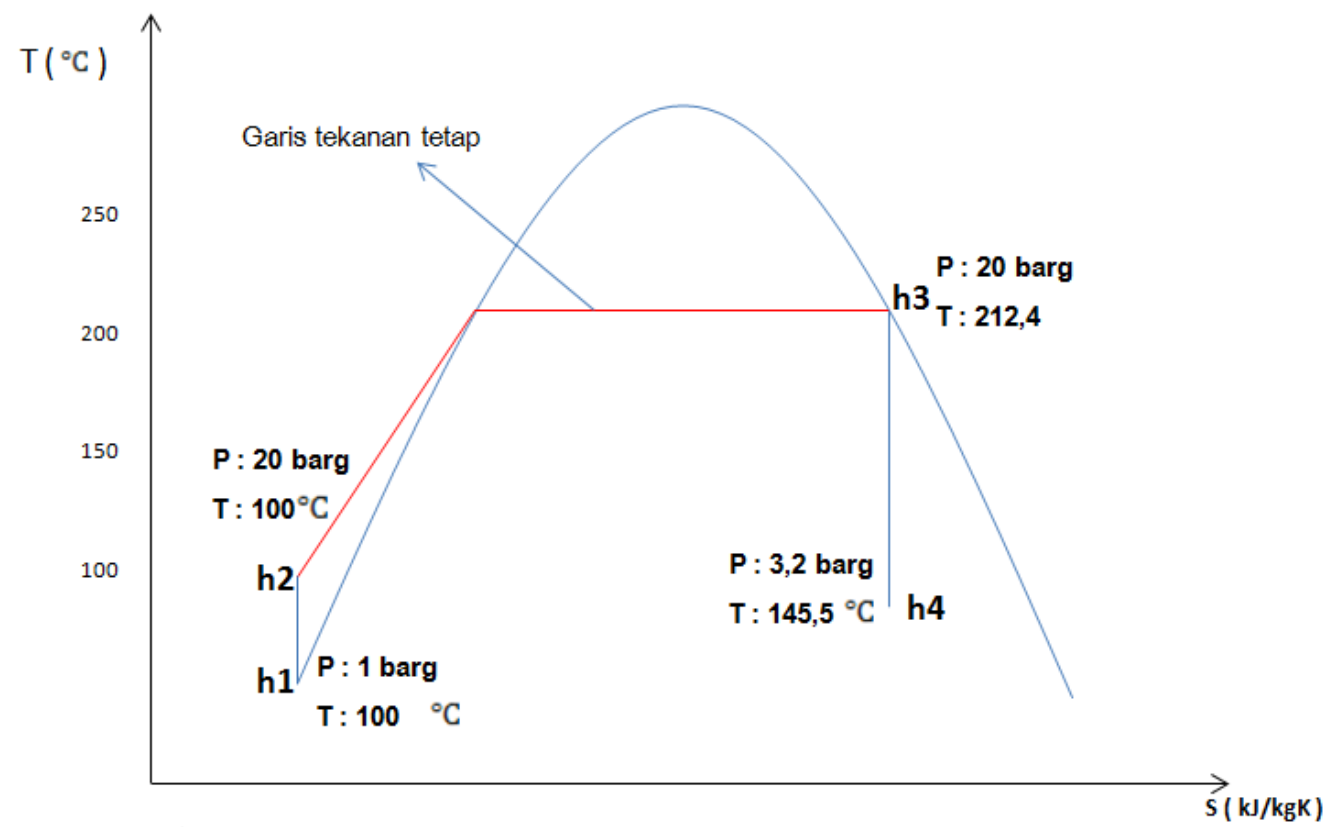

Gambar 5. Diagram T-S Boiler SRUM

Keterangan:

$\mathrm{h}_{1}$ : Adalah kondisi di mana air berada dalam deaerator pada tekanan 1 barg dengan temperatur $100^{\circ} \mathrm{C}$.

$\mathrm{h}_{2}$ : Kondisi air baru masuk ke boiler pada tekanan 20 barg namun temperatur masih $100{ }^{\circ} \mathrm{C}$.

$\mathrm{h}_{3}$ : Semua air yang ada telah berubah menjadi uap pada tekanan 20 barg dan temperatur $213^{\circ} \mathrm{C}$.

$\mathrm{h}_{4}$ : Kondisi di mana uap panas telah di ekspansikan oleh turbin sehingga temperatur dan entalphi nya menurun. 
Dari Gambar 5 tentang diagram T-S maka diperoleh rumus untuk mengitung jumlah panas yang diperlukan untuk menguapkan sejumlah air dalam boiler Pabrik Kelapa Sawit Sungai Rungai Mill adalah: Nilai h

$$
\begin{aligned}
\dot{Q} & : \dot{\mathrm{m}}_{\mathrm{air}} \mathrm{x}\left(\mathrm{h}_{3}-\mathrm{h}_{2}\right) \\
& : 1 \mathrm{~kg} \times(2799-421) \mathrm{kJ} / \mathrm{kg} \\
& : 2378 \mathrm{~kJ}
\end{aligned}
$$

a. Energi untuk menghasilkan steam 43,2 ton/jam ( $\left.Q_{\text {out }}\right)$

: $\mathrm{Q}_{\text {uap }} / \mathrm{kg} \mathrm{x} 43200 \mathrm{~kg} / \mathrm{jam}$

: $2378 \mathrm{~kJ} / \mathrm{kg}$ x $43200 \mathrm{~kg} / \mathrm{jam}$

: $102.729 .600 \mathrm{~kJ} / \mathrm{jam}$

b. Energi masuk $\left(Q_{\text {in }}\right)$

$:\left(\mathrm{Q}_{\text {fiber }} \times \dot{\mathrm{m}}_{\text {fiber }}\right)+\left(\mathrm{Q}_{\text {shell }} \times \dot{\mathrm{m}}_{\text {shell }}\right)$

$:(11027 \mathrm{~kJ} / \mathrm{kg} \times 10600,09 \mathrm{~kg})+(17167 \mathrm{~kJ} / \mathrm{kg} \times 2735,03 \mathrm{~kg})$

$:(116.887 .192,43)+(46.952 .260,01)$

: $163.839 .452,44 \mathrm{~kJ} / \mathrm{jam}$

c. Effesiensi Termal

$$
\begin{aligned}
& : \frac{\text { Qout }}{\text { Qin }} \times 100 \% \\
& : \frac{102.729 .600}{163.839 .452} \times 100 \% \\
& : 62,7 \%
\end{aligned}
$$

\section{KESIMPULAN}

Dengan efesiensi termal 62,7 \% untuk boiler PKS Sungai Rungau Mill dan specific steam consumption (SSC) turbin shinko PKS Sungai Rungau Mill maka diperoleh:

- $\quad$ Bahan bakar yang tersedia dan terpakai di Pabrik Kelapa Sawit Sungai Rungau Mill dapat dilihat pada Tabel 6.

Tabel 6. Hasil Pengukuran Beban Daya

\begin{tabular}{ccccc}
\hline Fuel & Tersedia $(\mathrm{kg})$ & Terpakai $(\mathrm{kg})$ & Sisa $(\mathrm{kg})$ & Komposisi \\
\hline Fiber & $1136 \mathrm{I}$ & 10600 & 761 & $79,49 \%$ \\
Shell & 5020 & 2735 & 2285 & $20,51 \%$ \\
\hline Jumlah & 16381 & 13982 & 3046 & $100 \%$ \\
\hline
\end{tabular}

Sedangkan kebutuhan energi Pabrik Kelapa Sawit Sungai Rungau Mill dapat dilihat pada Tabel 7.

Tabel 7. Kebutuhan Energi PKS Sungai Rungau Mill

\begin{tabular}{cccc}
\hline Bahan Bakar & Jumlah $(\mathrm{kg} / \mathrm{jam})$ & Nilai Kalor $(\mathrm{kJ} / \mathrm{kg})$ & Energi $(\mathrm{kJ} / \mathrm{jam})$ \\
\hline Serabut & 10600 & 17167 & 181.970 .200 \\
Cangkang & 2735 & 11027 & 30.158 .845 \\
\hline \multicolumn{3}{c}{ Total Energi } & 212.129 .045 \\
\hline
\end{tabular}

- $\quad$ Komposisi bahan bakar adalah 79,49\% serabut dan 20,51\% cangkang

- Pada kondisi normal sisa cangkang adalah 2286 kg/jam 


\section{UCAPAN TERIMA KASIH}

Ucapan terima kasih kami sampaikan kepada pimpinan Pabrik Kelapa Sawit Sungai Rungau PT Smart Tbk yang telah membantu kami dalam penyelesaian penelitian ini.

\section{DAFTAR PUSTAKA}

1) Michael J. Moran, Howard N. Shapiro, Bruce R. Munson, David P. DeWitt. (2002). Introduction to Thermal System Engineering: Thermodynamics, Fuid Mechanics, and Heat Transfer. United States of America: John Wiley \& Sons, Inc.

2) Reynold, C,R, Perkins, H, C terjemahan oleh harahap, F , (1994). Termodinamika Teknik", Jakarta: Erlangga.

3) Basiron Sukaimi, Ngan , Darus, Yusof, (2014) Palm Oil Research Institute of Malaysia.

4) Hariadi, Budi. 2017. Materi Pembekalan Magang. Dipresentasikan pada tanggal 3 Maret 2017. Bekasi. 